\title{
O confinamento do outro lado do oceano: a experiência de crianças e adolescentes durante a epidemia da Covid- I 9 na França
}

Fernanda Martinhago

\section{Resumo}

O presente artigo apresenta dados que retratam como foi o confinamento na França durante a epidemia da Covid-19, precisamente, para o público infanto-juvenil. O objetivo deste estudo foi aportar alguns elementos que possibilitem avançar na compreensão de como as crianças e os adolescentes vivenciaram a experiência do confinamento na França. A metodologia elegida para o desenvolvimento da pesquisa foi a etnografia virtual. Por meio dos materiais publicados nos jornais franceses e no site da Radio France Culture, foi possível ter contato com as experiências vivenciadas pelas famílias no confinamento. Estas publicações forneceram subsídios para compreender que manter as crianças e os adolescentes confinados somente no espaço familiar, ou seja, privados do lugar não familiar (escolas, parques, ruas), implica o processo subjetivo enquanto constituição de sujeito cujo progresso torna-se inviável de ocorrer sem transitar entre esses dois lugares.

Palavras-chave: Crianças. Adolescentes. Covid-19. Confinamento. Epidemia.

\section{Introdução}

Eu cheguei a Paris em setembro de 2019 para fazer um pós-doutorado na Université Paris 8 Vincennes-Saint-Denis. Durante um ano

I Bolsista de pós-doutorado pelo Programa de Cooperação Internacional CAPES-COFECUB junto à Université Paris 8 Vincennes Saint-Denis, França, e Universidade Federal de Santa Catarina (UFSC), Brasil. E-mail: martinhagofernanda@gmail.com

\section{(cc) Br}

Direito autoral e licença de uso: Este artigo está licenciado sob uma Licença Creative Commons. Com essa licença você pode compartilhar, adaptar, para qualquer fim, desde que atribua a autoria da obra, forneça um link para a licença, e indicar se foram feitas alterações. 
ficaria longe do meu país, o Brasil. Era início do outono, os franceses e turistas desfrutavam os dias ensolarados pelas ruas e cafés da cidade, os jardins ainda estavam repletos de flores, e me chamou atenção o quanto as crianças estavam embrenhadas neste cenário, brincando juntas descontraidamente pelos gramados e nos grandes brinquedos dos parques, que mais se parecem com obras de arte moderna. E como não notar um grupo de adolescentes, que fazia piquenique escutando música clássica, e outras duas jovens que tocavam violino no parque Montsouris? Uma realidade, no que diz respeito à infância e adolescência, muito diferente do que observo no Brasil, não me refiro apenas aos aspectos culturais que são peculiares a cada país, mas a uma experiência de liberdade. O psicanalista e professor, Leandro de Lajonquière, compartilha, em uma entrevista coordenada por Rodrigues e Reis (2018), a experiência de sua filha. Ele conta que com oito anos ela começou a ir para a escola sozinha, a qual se situava a três quarteiróes de sua casa, em um bairro fora do centro turístico de Paris. Acrescenta que, um pouco mais tarde, ela começou a se deslocar sozinha no bairro para outras atividades, como ir ao parque encontrar com a amigas, à piscina pública, à biblioteca, às aulas de esporte. Ele compara a infância atual em Paris com aquela que vivenciou na década de 1960, em Rosário, na Argentina, local em que nasceu.

É fato que, em Paris, com a chegada do inverno, os dias nublados e frios inibem um pouco os passeios por ruas e parques. Mas há diversas atraçôes culturais, museus, restaurantes, cafés, livrarias que são frequentadas pelos moradores e turistas que passeiam pela cidade. As manifestaçóes pelas praças, como a dos "Gilets Jaunes" (Coletes Amarelos) e greves em prol de melhorias no âmbito público, também fazem parte do cotidiano parisiense. No fim do outono, precisamente, no dia 5 de dezembro de 2019, começou uma grande greve por toda a França, que em princípio, duraria quatro dias, em prol de uma reforma da previdência, diferente da proposta pelo chefe de Estado francês. Transporte público, trem, metrô, tramway e ônibus ficaram paralisados ou funcionando de modo muito reduzido, o que fez com que grande parte da populaçáo preferisse ficar em casa do que perder muito tempo para se deslocar nos poucos ônibus lotados ou enfrentar o frio caminhando pelas ruas ou de bicicleta. A maioria das pessoas que circulava era porque tinha a obrigação de trabalhar; mesmo assim, muitos 
estabelecimentos permaneceram fechados ou abertos parcialmente porque aderiram à greve. Nota-se que, mesmo com todos os transtornos que a greve causou, a maioria dos franceses apoiou este movimento, porque concordava que era por uma boa causa. Este panorama começou a voltar a certa normalidade no início de fevereiro de 2020, ou seja, a greve durou dois meses, sendo uma das paralisaçóes mais longas dos últimos anos na França.

Os franceses ansiavam o fim do inverno e da greve, almejavam voltar a desfrutar os dias ensolarados pelas ruas, os piqueniques nos parques, os passeios à beira do rio Sena e o desabrochar das flores. Entretanto, estes tão desejados momentos, habitualmente vividos na primavera, foram inesperadamente interditados na vida dos franceses, pois o novo coronavírus já estava de "malas prontas" para sua viagem da China à França.

Em 12 de janeiro de 2020, a World Health Organization (WHO, 2020a) recebeu informaçóes transmitidas pelas autoridades chinesas sobre o novo coronavírus, a Síndrome Respiratória Aguda Grave 2 (Severe Acute Respiratory Syndrome Coronavirus - SARS-CoV-2), que causa um conjunto de infecçóes respiratórias. A Covid-19 se caracteriza como uma doença multiorgânica causada pelo vírus SARS-CoV-2 (COHEN, 2020). Vale lembrar que, em 2003, tivemos uma epidemia causada pelo vírus SARS-1, considerada a primeira epidemia do século XXI, portanto, a SARS-CoV-2 não se trata de uma patologia sem precedentes (BADIOU, 2020).

As notícias sobre a epidemia da Covid-19 vindas da China, em princípio, pareciam distantes do continente Europeu, mas rapidamente a população francesa foi alvo do vírus. Em 24 de janeiro de 2020, foram confirmados três casos de pessoas contaminadas pela Covid-19 na França, dois em Paris e um em Bordeaux. Estas pessoas chegaram ao Aeroporto de Paris (Charles de Gaulle) oriundas da China e haviam estado na cidade de Wuhan, local em que foram diagnosticados os primeiros casos da Covid-19. Os contatos dos três casos confirmados foram acompanhados durante 14 dias pela equipe de profissionais de saúde francesa, após o isolamento dos contaminados. Nenhum evento de transmissão secundária foi detectado até 12 de fevereiro de 2020. Portanto, considerando as estimativas do período de incubação da SARS-CoV-2, a probabilidade de casos secundários originários desses três primeiros casos na França é insignificante (BERNARD et al., 2020). 
Em 11 de março de 2020, o diretor-geral da WHO, Tedros Adhanom Ghebreyesus, anuncia em Genebra, na Suíça, que a Covid-19 é caracterizada como uma pandemia. Naquele momento, a doença do novo coronavírus já havia se espalhado por diversos continentes, afetando 114 países, com mais de 118.000 casos e 4.291 pessoas mortas (WHO, 2020b).

$\mathrm{Na}$ França, em 16 de março de 2020, devido ao rápido contagio da Covid-19, gerando um grande número de casos confirmados, 6.633 pessoas e, casos fatais 148 pessoas (RASTREADOR DA COVID-19, 2020), foram necessárias medidas rígidas para conter a disseminação da doença. Naquele dia, o presidente da República, Emmanuel Macron, declarou em discurso solene na televisão: "nous sommes en guerre" (nós estamos em guerra). Macron anunciou uma guerra sanitária, e explicou que não se luta contra um exército ou nem contra outra nação, mas contra um inimigo invisível que não se sabe como progride. E, assim, o Presidente decretou, a partir de 17 de março de 2020, o confinamento de toda a população, ou seja, o isolamento obrigatório para todas as pessoas no território francês, um contexto sem precedentes na história da França.

Nas regras do confinamento francês (MINISTÈRE DE L'INTERIEUR, 2020a), apenas os comércios de necessidades essenciais ficaram abertos, como supermercados, farmácias e padarias. Os atendimentos presenciais por motivo de problemas de saúde se restringiram aos casos em que não era possível a consulta a distância, em situação de patologias graves. As escolas e universidades ficaram fechadas, mas com os cursos realizados por meio de aulas a distância, a critério de cada professor. Os horários dos transportes públicos foram reduzidos. A permissão de deslocamento era apenas para aqueles que necessitavam trabalhar (médicos, enfermeiros, motoristas do transporte público, caixas de supermercados etc.), para quem precisava se deslocar por motivo familiar extremo, para assistência às pessoas vulneráveis ou em função da guarda de crianças. Foi permitido, para a população de modo geral, sair durante o tempo máximo de uma hora por dia, exceto das 10 às 19 horas, para atividades físicas individuais no perímetro próximo à residência de $1 \mathrm{~km}$, bem como para passear com animais domésticos. Todos os deslocamentos eram permitidos mediante o preenchimento de um formulário padrão estabelecido pelo 
governo francês. Primeiramente, o formulário era obrigatório apresentar em papel e assinado, caso houvesse solicitaçáo da polícia durante o trajeto; posteriormente, passou a ser um formulário eletrônico do site do governo francês, que poderia ser preenchido e apresentado à polícia pelo celular. A penalidade para quem desobedecesse às regras era desde uma multa de 135 euros até 3.700 euros, dependendo da infração, e reclusão de seis meses para quem fosse multado por quatro vezes no período de 30 dias (MINISTÈRE DE L'INTERIEUR, 2020a).

As crianças e os adolescentes não foram o público mais contaminado pela Covid-19, segundo Morand et al. (2020). O número de casos confirmados é muito baixo, se comparado ao número de adultos, assim como os casos graves e a mortalidade são inferiores. Em sua maioria, esse público infanto-juvenil que foi infectado, a transmissão, geralmente, ocorreu pela própria família (COHEN, 2020; MORAND et al., 2020). Cohen (2020) ressalta que as crianças são menos contaminadas, menos doentes e apresentam sintomas menos graves; portanto, não têm uma representação importante em relação à transmissão do SARS-CoV-2. Elas podem ser infectadas do mesmo modo que os adultos, mas apresentam a patologia de forma assintomática em apenas 10\% dos casos (COHEN, 2020).

Apesar de não ser o público-alvo do vírus, a liberdade das crianças e dos adolescentes, que eram acostumados a se deslocar tranquilamente pelo seu bairro, foi interditada, pois eles também foram obrigados a ficar confinados. O confinamento obrigatório é uma experiência nova para todos; portanto, não sabemos qual o impacto que pode causar na população. Por isso, considero que o desenvolvimento de pesquisas sobre esta temática são de extrema relevância para se pensar melhores estratégias, no caso de novas pandemias. Diante desse contexto, o objetivo deste estudo é aportar alguns elementos que possibilitem avançar na compreensão de como as crianças e os adolescentes vivenciaram a experiência do confinamento durante a epidemia da Covid-19 na França.

\section{Percurso metodológico}

A etnografia virtual (HINE, 2004) foi elegida como metodologia de pesquisa para ter acesso ao cotidiano da populaçáo confinada na França, 
um modo de "entrar na casa" dos franceses, durante o confinamento (17 de março a 11 maio de 2020). O mundo virtual propiciou uma transformação no contexto da pesquisa, de modo que "os etnógrafos podem se libertar do "lugar" por meio da internet" (ANGROSINO, 2009, p. 120). Mann e Steward (2000) averiguaram como as tecnologias da internet são utilizadas em pesquisas qualitativas, e salientam o potencial da comunicação entre os sujeitos, incluindo textos, imagens, vídeos, gráficos, voz etc. Por meio destes materiais publicados nas mídias virtuais, foi possível ter contato com as experiências vivenciadas pelas famílias no confinamento, com ênfase nas crianças e nos adolescentes. As publicaçóes dos jornais franceses ( $L e$ Monde; Liberatión; Le Parisien; 20 Minutes e CNews), disponíveis gratuitamente na internet e as informaçóes publicadas pela Radio France Culture propiciaram o contato direto com narrativas, textos, entrevistas, desenhos, provenientes de crianças e adolescentes, dos pais e profissionais implicados com a temática do confinamento. Essas publicações retratavam a vida confinada na França, salientando os principais aspectos que interferiam no cotidiano durante a pandemia.

O principal interesse desta pesquisa foi buscar elementos para compreender como foi vivenciada a experiência de confinamento de crianças e adolescentes durante a epidemia na França. Portanto, dentre as publicaçôes lidas, foram descartadas aquelas que se tratavam restritamente de recomendaçóes e orientaçóes para os pais lidarem com os filhos durante o confinamento (grande parte das publicaçóes). O objetivo foi ter um contato o mais próximo possível com o público infanto-juvenil e os pais, assim como saber o posicionamento de profissionais sobre possíveis implicaçóes subjetivas do confinamento.

Por esse motivo, para ter acesso a narrativas do público infanto-juvenil, foi selecionado uma publicação da Radio France Culture (REALE, 2020), cuja proposta foi saber como se sentiam as crianças e os adolescentes na quarta semana de confinamento, abordando quais eram suas preocupaçôes, se estavam se sentindo distantes dos familiares e amigos, sentindo falta da escola, se tinham projetos; enfim, o que podiam contar sobre a experiência do confinamento. Participaram 20 crianças e adolescentes, entre 6 a 14 anos, as quais enviaram textos, áudios e desenhos sobre o seu cotidiano 
no confinamento. As narrativas apresentadas pelas crianças e pelos adolescentes tiveram o contraponto de uma psicóloga e psicanalista, Danielle Dalloz. Alguns desenhos estão expostos no artigo com o intuito de obter um olhar sobre o que representou o confinamento para essas crianças e esses adolescentes, sem a pretensão de fazer uma análise profunda do desenho infantil, o que demanda de uma teoria específica para tal finalidade, e, principalmente, uma escuta dos pequenos autores. Já o acesso às narrativas dos pais, foi por meio do jornal Le Monde (CONFINEMENT, 2020), o qual disponibilizou um chat para os pais dialogarem com uma psicóloga clínica, Aline Nativel, sobre questóes emocionais dos seus filhos durante o confinamento; houve 16 participantes. O jornal Le Parisien (PAYET, 2020; PUEYO, 2020) propiciou o contato com duas situaçóes: um adolescente com autismo e uma jovem com múltiplas deficiências. O jornal 20 Minutes (GABRIEL, 2020) também possibilitou o acesso à situação de crianças com deficiências e os desafios com o confinamento. Os nomes das crianças, dos adolescentes e dos pais permanecerão de acordo com os documentos, por se tratar de conteúdos públicos de livre acesso na internet. No que se refere aos profissionais, além das duas psicólogas citadas anteriormente, foram selecionadas quatro entrevistas publicadas sobre o confinamento de crianças e adolescentes. Os entrevistados estão identificados pelo nome e suas respectivas profissões, conforme segue: David Le Breton, antropólogo e sociólogo - Radio France Culture (TOURRET, 2020); Hélène Romano, psicóloga - Cnews (TAVEIRA, 2020); Stephan Eliez, Psiquiatra e professor de psiquiatria da criança e adolescente - Libération (VECRIN, 2020); e Claude Halmos, psicanalista - Radio France Culture (MOGHADDAM, 2020).

No decorrer do texto, todo o material referente às publicaçóes citadas que forneceram elementos para avançar na compreensão do objeto de pesquisa será mencionado o nome do jornal ou da rádio para que se diferencie de referências teóricas. A escrita no idioma original encontra-se em rodapé.

Considera-se que, por se tratar de uma temática nova para todos, é importante angariar as diferentes perspectivas, tanto as provenientes das experiências pessoais, quanto os saberes dos especialistas. Assim, os conteúdos foram divididos em cinco temáticas, contemplando os conteúdos 
dos três núcleos que interessam à pesquisa: 1) as crianças e os adolescentes; 2) os pais; e 3) os profissionais. As temáticas que emergiram das narrativas e dos desenhos foram: $\mathrm{O}$ inimigo invisível; $\mathrm{A}$ família à qual pertenço; O computador não é uma escola; O risco psíquico; e A violência velada.

\section{0 inimigo invisível}

A declaração de que "nós estamos em guerra" contra um inimigo invisível, anunciada por Emmanuel Macron, parece que ecoou no universo infantil, propiciando que as crianças criassem mecanismos imaginários de modo que pudessem combater o vírus. $\mathrm{O}$ medo da doença, da morte, da perda de familiares e amigos fez parte do cotidiano durante o confinamento. As narrativas tanto dos pais, quanto das crianças revelam os sentimentos que afloraram durante a epidemia, bem como o que passou no imaginário infantil em relação ao vírus.

Milena (8 anos) revela que teve o pai afetado pela Covid-19 e hospitalizado por 10 dias; posteriormente, ele se recuperou e retornou para casa. Ela contraiu o vírus também, mas teve sintomas leves. Milena imagina que seu corpo venceu o vírus, que ela entende da seguinte forma: "Eu penso em uma espécie de bola grande com muitas pústulas. Ela se agarra e se multiplica em todas as partes do corpo"; relata também que, para derrotar a "grande bola", ela lava as mãos e respira o ar do jardim, "já que a sua casa está cheia de vírus” - Radio France Culture (REALE, 2020)².

As narrativas dos pais apresentam uma preocupação em relação às mudanças de comportamento de seus filhos durante o confinamento. Uma mãe relata que seu filho de 5 anos era uma criança calma, mas ficou agressivo, náo aceita as restriçóes e está frequentemente de mau-humor. Ele grita em casa, ao se referir ao coronavírus: "Eu vou te matar"”. A mãe conta que a brincadeira atual dele é matar um invasor extraterrestre que é cúmplice do coronavírus. Apesar da preocupação da mãe, sob a perspectiva psicológica, Aline Nativel - Le Monde (CONFINEMENT, 2020) afirma que é um excelente

\footnotetext{
2 "Je pense à une espèce de grosse boule avec plein de pustules. Elle s'accroche et elle se multiplie dans toutes les parties du corps"; "vu que la maison est pleine de vírus".

3 Je vais telvous tuer.
} 
sinal de saúde psíquica, pois essa criança consegue expressar e lidar com a situação imposta pelo coronavírus por meio de sua imaginação e brincadeiras.

A psicóloga Hélène Romano - Cnews (TAVEIRA, 2020) menciona que a epidemia do coronavírus provoca constantemente um estado de ansiedade, por motivos diversos: medo do desconhecido, medo da doença, medo da morte, medo de perder um familiar ou um amigo, medo de perder o emprego, medo da crise econômica; enfim, gera uma instabilidade na vida cotidiana.

As dificuldades para as crianças e os adolescentes dormirem foi outra queixa apresentada pelos pais. Uma mãe relata que sua filha de 4 anos tem muita dificuldade para dormir; pergunta se os "micróbios" não irão vir, referindo-se ao vírus SARS-CoV-2. Outra questáo, em relação às crianças pequenas, é o medo das pessoas com máscaras: um cenário novo para todos (CONFINEMENT, 2020). A existência do inimigo invisível gera um estado de ansiedade, por não saber se ele irá vir ou se, de repente, já está ali. Fato que ninguém pode seguramente informar. $\mathrm{O}$ uso de máscaras, além de modificar totalmente o aspecto das pessoas e esconder a expressão facial, demonstra que qualquer um está vulnerável ao vírus; por isso, a proteção.

O medo prevalece em vários aspectos. Segundo a mãe de uma menina de 5 anos, a criança sente medo que seus colegas e seus amigos sejam afetados pela Covid-19 e venham a morrer, e depois, não os reencontrará no retorno à escola. Além disso, o medo de retornar à escola e ser contaminado pelo vírus também aparece nas narrativas dos pais. Preocupação que, provavelmente, atormenta muitas famílias e as próprias crianças e os adolescentes (CONFINEMENT, 2020).

A psicóloga Aline Natival (CONFINEMENT, 2020) explica que este sentimento de medo pode se manifestar de diversas formas, sendo uma delas o comportamento de regressão das crianças (falar como um bebê, assistir programas de bebê, voltar a usar a chupeta etc.) conforme apareceu nas queixas de diversos pais. Ela explica que voltar a se posicionar como um bebê é uma forma de buscar a proteção dos pais.

A foto da casa construída com o brinquedo Lego (Figura 1) por Aaron (6 anos), enviada à Radio France Culture (REALE, 2020), mostra a Covid-19 na porta enquanto todos estão confinados em casa, sem poder sair. 


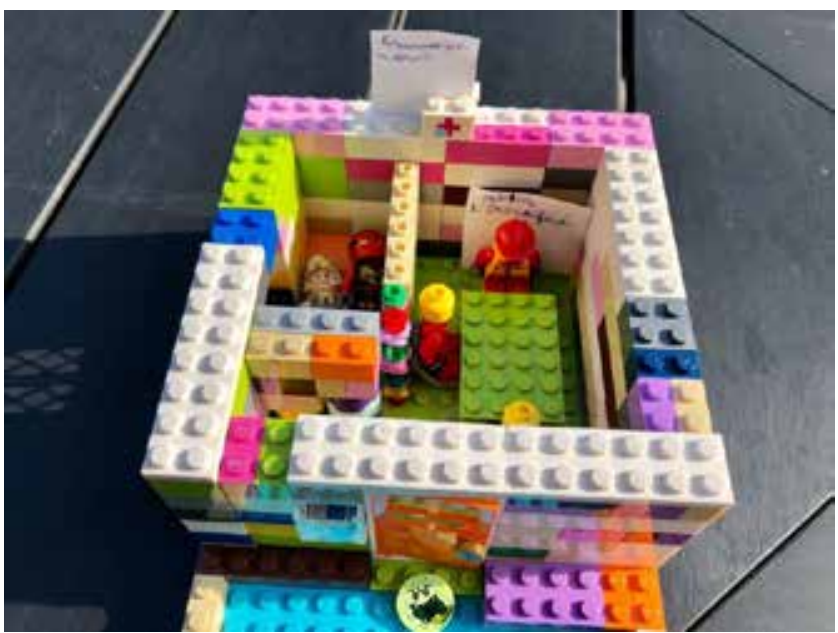

Figura I - "Vírus Vilão" (Vilain vírus) - Aaron (Radio France Culture)

Fonte: Reale (2020).

O efeito midiático da Covid-19 é um tema apontado pelo público infanto-juvenil, pois o mundo parece girar em torno apenas desta doença. As informaçóes diárias passadas pela mídia indicando o número de pessoas infectadas, de mortes nas últimas 24 horas e o cenário caótico em outros países também afetaram a saúde psíquica do público infanto-juvenil.

Como podemos observar na narrativa de Lena (13 anos), ela revela que náo gostaria de ter acesso a tantas informaçóes sobre a pandemia, antes se sentia protegida pelos seus pais por receber apenas conteúdos que considerava apropriados para sua idade. Mas, no momento, relata que recebe informaçóes que são relacionadas ao coronavírus e suas consequências. Tudo está direcionado pelo mesmo tema: Covid-19. Ela afirma: "Nós estamos confinados não apenas fisicamente, mas também mentalmente, porque tudo constantemente nos leva de volta à mesma coisa. Eu me sinto privada da minha liberdade" - Radio France Culture $\left(\right.$ REALE, 2020) ${ }^{4}$. É possível que Lena esteja se referindo náo apenas à privação da liberdade de sair de casa mas também da liberdade de pensar, criar, refletir sobre outros assuntos que não dizem respeito ao coronavírus.

4 Nous sommes confinés non seulement physiquement mais aussi mentalement car tout nous ramène sans cesse à la même chose. Je me sens privée de ma liberté. 
A psicóloga Hélène Romano - Cnews (TAVEIRA, 2020) argumenta que a cobertura da mídia com as transmissóes de informaçóes, que nem sempre são consistentes, perpetuam a ansiedade na população. Da mesma forma, as disparidades nas decisóes políticas promovem um estado de insegurança, porque as pessoas não sabem se estão adequadamente informadas, o que gera um sentimento de desamparo.

Diante da diversidade de mídias, somos bombardeados diariamente com inúmeras informações que, algumas vezes, são contraditórias. Isso promove um estado de total insegurança. Entretanto, esta situação é ainda mais grave quando se trata de uma pandemia, de uma patologia que, em muitos casos, é fatal. $\mathrm{O}$ medo de contrair a doença, a insegurança dos gestores sanitários em relação ao controle da transmissibilidade, a falta de equipamentos médicos, como os respiradores, a falta de leitos em hospitais para internação de uma grande demanda, o desconhecimento científico sobre o vírus, são alguns dos aspectos que produzem ansiedade não apenas nos adultos, mas também em crianças e adolescentes.

\section{$4 \mathrm{~A}$ família à qual pertenço}

Estar em casa com a família foi uma experiência distinta para cada criança ou adolescente. Para alguns, um momento de simplesmente estar juntos, para outros estreitou os laços familiares, enquanto houve aqueles que gostariam de estar um momento distante de todos. O desenho de Elisa (8 anos) retrata a realidade do confinamento para a maioria das pessoas: ficar em casa! - Radio France Culture (REALE, 2020).

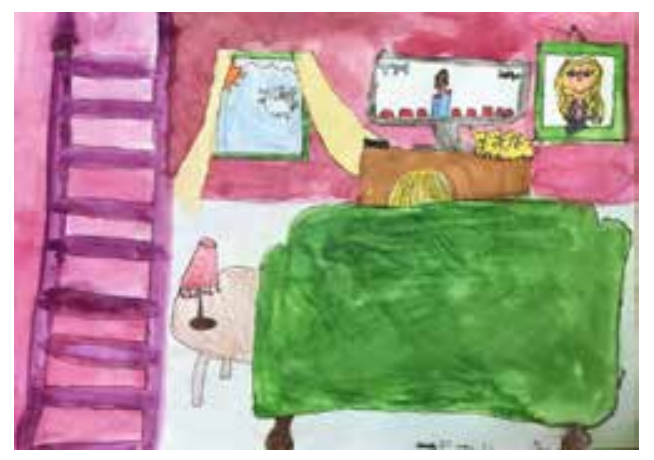

Figura 2 - "Corona casa" (Corona Maison) - Elisa (Radio France Culture)

Fonte: Reale (2020). 
A vida restrita ao núcleo familiar, para algumas crianças não é suficiente, uma vez que estão acostumadas a conviver com os avós, os primos, e os demais membros da família. Célia (11 anos) expressa o que sente na situação de confinamento:

A família, para mim, está muito antes de amigos, de amigas e dos namorados. O fato de não ver os primos, como na Páscoa, por exemplo, me deixa triste e me estressa um pouco, porque náo é como de costume. Isso faz refletir sobre muitas coisas e nos damos conta que realmente nos preocupamos com eles. - Radio France Culture. (REALE, 2020) $)^{5}$.

\section{A psicanalista Claude Halmos - Radio France Culture (MOGHAD-} DAM, 2020) cita que os rituais, ou seja, algo que se repete da mesma maneira, todos os dias ou todas as semanas, em que a criança esteja acostumada, torna-se uma referência para elas, um modo de estruturar o tempo e a continuidade da vida, transmitem a sensação de segurança. Por isso, quando algo é interrompido repentinamente, a criança pode se desestabilizar, diz a psicanalista.

Penso que, não apenas a criança, mas qualquer pessoa, qualquer família sofre uma certa desestabilidade com a interdição, conforme podemos observar na experiência vivenciada por Marie (idade não revelada). Ela também percebe a importância da família durante o confinamento, pois a menina ficou junto ao pai, uma tia e um tio. A sua mãe e sua irmã de dois anos ficaram no Haiti, impossibilitadas de voltar à França. Marie fala sobre a falta que sente das duas e o receio de que a irmá pequena náo a reconheça mais:

Eu percebi, com o confinamento, que minha máe fazia muito por mim todos os dias e, realmente, sinto muita a falta dela. Sinto falta até mesmo quando ela gritava comigo. Só posso ligar para ela três vezes por semana por causa da falta de energia lá. Eu também sinto falta da minha irmãzinha. É como se ela crescesse sem mim. Tenho medo de que ela não me reconheça quando voltar - Radio France Culture (REALE, 2020) ${ }^{6}$.

5 La famille, pour moi, ça passe bien avant les copains, les copines et les amoureux. Le fait de ne pas voir [les cousins], pour Pâques par exemple, ça me rend triste et ça me stresse un petit peu, dit-elle, car ce n'est pas comme d'habitude. Ça fait réfléchir à beaucoup de choses et on se rend compte qu'on tient vraiment à eux.

6 J'ai réalisé, avec le confinement, que ma mère est beaucoup là pour moi tous les jours et que finalement, elle me manque. Ça me manque même quand elle me crie dessus. Je ne peux l'appeler que trois fois par semaine à 
$\mathrm{O}$ anúncio do confinamento pelo chefe de Estado Francês foi repentino, uma paralisação imediata de todas as atividades e de deslocamentos, o que fez muitas pessoas permanecerem "longe de seus lares, famílias separadas pela surpresa da pandemia. Claude Halmos - Radio France Culture (MOGHADDAM, 2020) compara o efeito da epidemia como um terremoto, visto que, para se levantar, o ser humano precisa de um solo real, necessário para apoiar seus pés, e o outro simbólico, que é constituído pelo lugar que ocupa na história familiar, as construçóes da vida privada e social, pela qual se constitui sua identidade. $\mathrm{O}$ confinamento causa uma fratura nesta estrutura, transforma a vida familiar bruscamente, privando todos do exterior, da vida profissional e social.

Porém, Marie considera que o lado positivo do confinamento é estar junto ao pai: "Assistimos a filmes, comemos pipoca com crepes. Conversamos mais e rimos mais. Gostaria que continuasse quando o confinamento terminasse, porque é bom passar um tempo com ele" - Radio France Culture (REALE, 2020) ${ }^{7}$.

Enquanto Marie aproveita os momentos com o pai, outras crianças gostariam de estar por alguns momentos distantes de suas famílias, conforme expressa Ismaël (11 anos):

\section{Sozinho}

"A cidade dos meus sonhos seria uma vila. Eu gosto mais de vilas, acho menos barulhentas. Minha vila seria um lugar onde eu moraria sozinho. Eu prefiro estar sozinho, não há risco de discutir e podemos ficar tranquilos. E depois, ficar sozinho, eu gosto disso, porque ninguém pode opinar, além de você. Na minha vila, haveria uma loja, uma academia, uma casa ecológica e um cinema. Tudo seria meu. Eu poderia fazer o que quisesse quando eu quisesse. Ninguém poderia me dizer nada. O governo não conheceria esta vila. Esta vila, eu chamaria: "Sozinho". Eu sei que minha ideia pode parecer chocante para algumas pessoas. Mas, neste momento, nós estamos todos trancados em casa com nossas famílias e todo mundo sonha em ficar sozinho - Radio France Culture (REALE, 2020) ${ }^{8}$.

cause des coupures de courant là-bas. Ma petite soeur me manque aussi. C'est comme si elle grandissait sans moi. J'ai peur qu'elle ne me reconnaisse pas quand elle reviendra.

7 On regarde des films, on mange du pop-corn avec des crêpes. On parle davantage et on rigole plus. J'aimerais que cela continue quand le confinement sera terminé parce que ça me fait du bien de passer du temps avec lui.

8 Seul. La ville de mes rêves serait un village. J'aime plus les villages, je trouve ça moins bruyant. Mon village serait un endroit où je viurais seul. Je préfère être seul, on ne risque pas de se disputer et on peut être tranquille. 
Ismael cria uma vila imaginária onde gostaria de estar no momento do confinamento. E é interessante que este lugar seria desconhecido do governo, ou seja, sem regras de confinamento. Essas normas, para alguns adolescentes, são extremamente difíceis, pois representam ficar longe dos amigos e mais tempo com a família. E como Ismael mesmo ressalta: "todo mundo sonha em ficar sozinho".

O sociólogo e antropólogo David Le Breton - Radio France Culture (TOURRET, 2020) alerta que, apesar de a adolescência ser um período da vida caracterizado pela transgressão, no confinamento o adolescente deve estar ciente de que o perigo não é apenas para ele, pois é possível transmitir para os demais membros da família e outras pessoas; por isso, seguir as regras de reclusão é importante. Breton nos lembra que o confinamento não significa que somos vítimas de uma tragédia, mas estamos com a situação sob controle.

O psiquiatra e professor Eliez Stephan - Libération (VECRIN, 2020) considera que as crianças experimentam o confinamento da mesma forma que os adultos no que diz respeito a estar sem vida social. Mas, de acordo com as idades, é diferente. As crianças mais novas que frequentam o jardim de infância, assim como aquelas que vão à escola, aproveitam a oportunidade para passar mais tempo com os pais. Para os adolescentes, é mais difícil. Geralmente, alguns conseguem compensar esse isolamento com as redes sociais, entretanto, nem todos os adolescentes têm o mesmo lugar neste espaço virtual. Estes, provavelmente, se encontraráo mais marginalizados.

Et puis être seul, j'aime ça, car personne ne peut donner son avis à part toi. Dans mon village, il y aurait un magasin, une salle de sport, une maison écologique puis un cinéma. Tout serait à moi. Je pourrais faire ce que je veux quand je le veux. Personne ne pourrait rien me dire. Le gouvernement ne connaîtrait pas ce village. Ce village, je le nommerais: "Seul". Je sais que mon idée peut paraître choquante pour certaines personnes. Mais en ce moment nous sommes tous enfermés chez nous en famille et tout le monde rêverait d'être seul. 


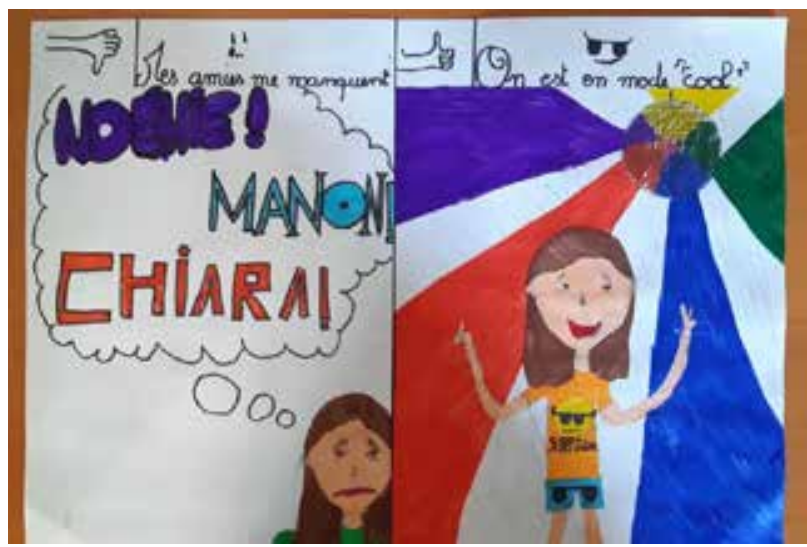

Figura 3 - "Por que gostamos de ficar em confinamento e por que não gostamos" (Pourquoi on aime être en confinement et pourquoi on n'aime pas) - Leïla (Radio France Culture)

Fonte: Reale (2020).

O desenho de Leila, 11 anos - Radio France Culture (REALE, 2020), mostra o sentimento de ambiguidade no confinamento. Por um lado pode ser "legal" (cool) estar em casa, sem precisar ir para escola e outros compromissos; por outro, há um sentimento de tristeza e solidão por estar distante dos amigos.

A convivência com a família foi uma experiência singular para cada um. Para algumas crianças foi uma oportunidade de estar mais tempo com a família, já para outros foi uma situação desgastante passar tanto tempo juntos. O fato de a "empresa" (trabalho remoto dos pais) e a "escola" (aulas a distância dos filhos) serem transferidas repentinamente para um mesmo espaço - a casa da família - demandou uma adaptação abrupta para todos, para além apenas da convivência familiar. Essa situação agregou os problemas que dizem respeito à vida profissional dos pais e as dificuldades de aprendizagem dos filhos com o improvisado formato de ensino a distância, que foi uma experiência nova tanto para professores quanto para estudantes.

\section{0 computador não é uma escola}

A frase "O computador não é uma escola" é uma tradução de uma imagem que circulou nas redes sociais durante o confinamento. Esta ima- 
gem é a fotografia de um notebook e, logo abaixo, a frase "Ceci n’est pas une école", exposta em um quadro com uma moldura antiga e uma senhora observando. Considero essa imagem uma manifestação genial! A escola de forma alguma pode ser substituída por um computador; mas, o que ocorreu durante a epidemia da Covid-19, com aulas a distância, foi uma medida emergencial que deve ficar na história. Penso que isso requer uma reflexão sobre as discussões em relação ao ensino a distância como uma possível realidade futura, no que se refere à educação infanto-juvenil.

Lajonquière (RODRIGUES; REIS, 2018) revela ter uma desconfiança da educação a distância, e diz na entrevista: "O saber em si não cola, o que "dá liga" é o desejo que não é outro que seu avesso". No seu livro "Figures de l'infantile", Lajonquière (2013) apresenta os elementos implicados no processo de ensinar, bem como na educação de modo geral. Na perspectiva psicanalítica, educar ultrapassa o ato de estimular, interagir ou mediar, conforme os termos usados corriqueiramente. Educar implica instaurar a possibilidade da emergência de efeitos de subjetivação na criança, explica o autor. Lajonquière afirma, ainda, que educar implica: “[...] transmitir marcas de pertencimento, de filiaçáo, que possibilite à criança conquistar para si um lugar de enunciação em nome próprio no campo da palavra e da linguagem ou, se preferirem, um lugar de palavra numa história" (RODRIGUES; REIS, 2018, p. 446).

Por meio dos textos de Lajonquière é possível observar o quão a experiência escolar de uma criança, isto é, o fato de se lançar ao náo familiar aquilo que é diferente da mesmice familiar de todos os dias, está imbricado na construção dos tempos da infância e da adolescência atuais. $\mathrm{O}$ desaparecimento desse outro cenário cotidiano (não familiar) de forma abrupta, seguramente, deixou marcas na vida das crianças e dos adolescentes que ainda não é possível precisar. Por enquanto, lembrar como ocorreu esse processo e escutar as experiências vivenciadas por eles é o que considero plausível fazer.

A interdição escolar começa, precisamente, em 18 de março de 2020, quando a United Nations Educational, Scientific and Cultural Organization (UNESCO) estimou que 107 países implementaram o fechamento nacional de escolas em função da pandemia da Covid-19, afetando 862 
milhóes de crianças e jovens, aproximadamente metade da população estudantil global (VINER, 2020).

Um estudo realizado durante a epidemia da SARS, em três grandes cidades, Pequim, Hong Kong e Cingapura, mostrou que o fechamento das escolas não contribuiu para o controle da propagação do vírus (VINER, 2020). Esta prática de fechar as escolas é baseada em evidências e suposiçóes de que nos surtos de gripe, reduzindo os contatos sociais entre os estudantes, seja possível interromper a transmissão. Viner (2020) explica que a maioria dessas açóes são realizadas com base em suposiçóes de que os benefícios aparentes em os surtos de gripe também, provavelmente, são válidos para a Covid-19. Entretanto, há várias razões teóricas pelas quais o fechamento de escolas pode ser menos eficaz na Covid-19 do que em surtos de gripe. Uma das razóes é que as crianças contribuem mais para a transmissão de influenza do que os adultos, e referente à Covid-19 a proporção de casos é mais baixa do que a esperada para esta população. Estes, quando infectados, permanecem assintomáticos ou com sintomas leves. Os estudos que preconizam o fechamento de escolas no caso de surtos de gripe se baseiam em suposiçóes de que a proporção de casos transmitidos nas escolas é relativamente alta; todavia, não se pode presumir que esses modelos sejam informativos no que diz respeito à eficácia da Covid-19. Todavia, Cohen (2020) ressalta que ainda é cedo para afirmar qual o impacto do fechamento das escolas em relação à propagação do vírus SARS-CoV-2.

A discussão da comunidade científica sobre a eficácia do fechamento das escolas para interromper a transmissibilidade da Covid-19, sem dúvida, é um tema de extrema importância, pois as crianças e os adolescentes passam a ter as aulas a distância, transmitidas pelo computador, o que não substitui a aula presencial na escola. Em alguns contextos, o acesso à internet e a disponibilidade de ter um computador exclusivo para assistir as aulas, é nula, situação que desestimula a continuar os estudos, um grande risco de evasão escolar.

O desenho de Violeta, 10 anos - Radio France Culture (REALE, 2020), demonstra que o confinamento significa estar privada de passear, de viajar, de estar com os amigos e também de frequentar a escola. Portanto, o computador está distante de substituir a escola. E o tempo em que 
os estudantes passam tendo aulas a distância tem um significado distinto do aprendizado na escola. Violeta também ressalta a ameaça de contrair a Covid-19, que é preciso usar máscara e gel, e principalmente, ficar em casa. $\mathrm{O}$ desenho é um resumo do que se restringiu à circulação entre o privado e o público, durante o confinamento.

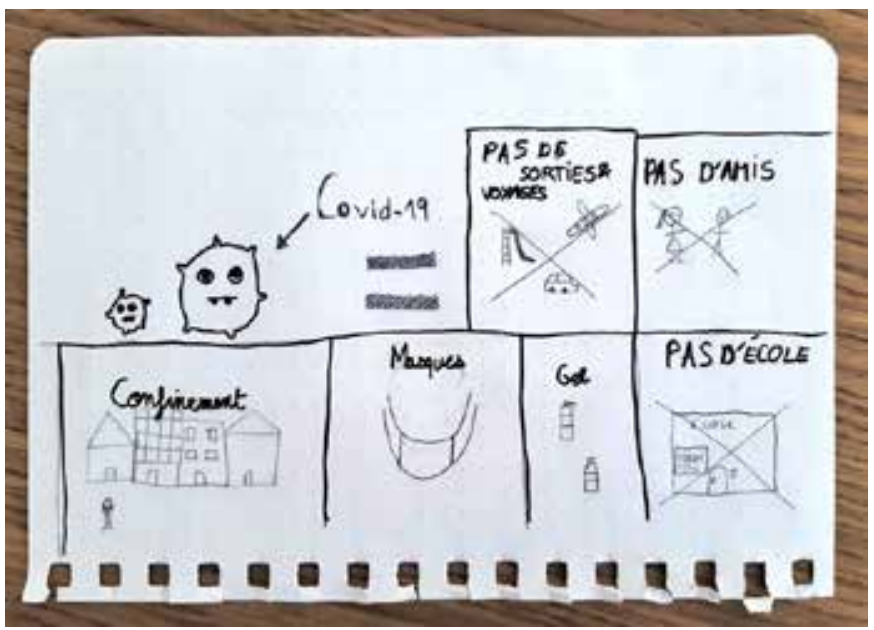

Figura 4 - "O Covid para mim" (Mon Covid à moi). - Violeta (Radio France Culture)

Fonte: Reale (2020).

O aprendizado longe da escola é uma das dificuldades apresentadas pelas crianças e pelos adolescentes, os quais percebem a importância dos professores de forma presencial. Sacha (11 anos) diz: "Meus pais não entendem minha lição de casa; então, tudo leva mais tempo" - Radio France Culture (REALE, 2020) 9

Assim como, Leila (11 anos) da mesma idade explica: "Porque o professor não está lá para nos explicar quando temos dificuldades. Os pais devem trabalhar a distância; então, devemos ser independentes"10.

9 Mes parents ne comprennent pas mes devoirs, donc tout est plus long

10 Parce que la maîtresse n'est pas là pour nous expliquer quand on a des difficultés. Les parents doivent télétravailler donc on doit être autonomes. 
Devido às teleconferências, ela pode ver sua professora todos os dias, e considera que é "onde nós vamos aprender as coisas" - Radio France Culture (REALE, 2020).

Alguns pais se queixaram que, além do trabalho remoto, tinham que ajudar seus filhos nas atividades que eram passadas pelas aulas a distância; isso foi considerado extremamente desgastante em algumas famílias. A falta de socialização entre as crianças também é citada como prejudicial ao bem-estar delas (CONFINEMENT, 2020).

O sociólogo e antropólogo David Le Breton - Radio France Culture (TOURRET, 2020) fala sobre como o confinamento dos adolescentes e como esta situação apenas acentua tendências já observadas nos núcleos familiares. O confinamento dos adolescentes junto aos familiares pode ser oportuno para estreitar os laços e melhorar as relaçóes entre pais e filhos, observar o quanto um pode dar apoio ao outro diante deste contexto de pandemia. Por outro lado, aquelas famílias em que o exercício da autoridade é problemático pode ser extremamente complicado este tempo de convívio juntos, inclusive porque as tarefas escolares são realizadas somente em casa e sob a responsabilidade dos pais de cobrarem dos filhos, acrescenta Breton.

O confinamento traz à tona as desigualdades sociais. Os riscos são diferentes para quem vive em uma família que apresenta laços consistentes, onde é possível apoiar uns aos outros, se vivem em uma casa grande com jardim, cada membro da família possui um notebook para estudar ou trabalhar, um celular para os contatos virtuais com os amigos e demais familiares. Já os menos favorecidos passam por uma experiência de confinamento mais difícil, com muitas pessoas convivendo 24 horas no mesmo cômodo; algumas vezes, com situações de violência doméstica, alcoolismo, pouca instrução dos pais para auxiliar nas atividades escolares a distância, falta de computador para desempenhar o trabalho remoto ou estudo, falta de internet, ou seja, condições que produzem um ambiente muito mais tenso para o confinamento. O psiquiatra e professor Stephan Eliez - Libération (VECRIN, 2020) alerta que a desigualdade nos contextos familiares

II Où on va apprendre des choses. 
exige ajustes para a situação de confinamento, considerando todas as dimensôes; caso contrário, o risco social, humano e psicológico pode exceder o risco à saúde. As palavras de Eliez ressaltam as necessidades de ajustes para o confinamento em função dos riscos que isso pode causar, o que considero extremamente relevante. Entretanto, o contágio de uma doença que pode ser fatal é algo que precisa ser evitado de qualquer modo.

Vale salientar que, quando falamos de risco à saúde, isso se refere a uma probabilidade, que de modo geral, pode equivaler para mais ou para menos de 50\%, mas náo a totalidade dos danos (MARTINHAGO; ROMANÍ, 2019). É com base nesta concepção que abordo a discussão sobre risco psíquico.

\section{0 risco psíquico}

As preocupaçóes durante a epidemia circularam em torno das seguintes circunstâncias: medo de sair de casa e contrair uma patologia que pode ser fatal, ser um portador assintomático do vírus e contagiar outras pessoas, isolamento social, saúde de familiares e amigos, entre outras. Mediante este contexto, os riscos de danos psíquicos são inúmeros. Segundo o Stephan Eliez - Libération (VECRIN, 2020), o confinamento agrava tensóes emocionais, como a ansiedade relacionada ao vírus ou o estresse gerado pelo trabalho remoto. As condiçóes das famílias não são iguais no confinamento, com as crianças em casa e, às vezes, somados ao trabalho, a vida familiar pode se tornar um campo de batalhas. Os problemas que existiam antes não desapareceram, eles estão em prisão domiciliar: conflitos do casal, preocupações financeiras, crianças com sofrimento psíquico, preocupação com o trabalho dos pais, a incerteza profissional, os estudos das crianças; enfim, o confinamento agrava as tensóes emocionais e as angústias associadas ao vírus, complementa Eliez.

O agravamento destas tensóes pode levar a situaçóes de extremo risco à vida, como podemos observar no caso em que a psicóloga Aline Nativel - Le Monde (CONFINEMENT, 2020) recebe uma espécie de pedido de "socorro" de uma mãe. Ela diz que seu filho está deprimido e apresenta pensamentos suicidas, ele se recusa a teleconsultar um psicólogo ou um médico. A psicóloga alerta para que a mãe, independentemente da 
vontade de seu filho, leve-o para consultar com um profissional de saúde. Vale lembrar, que durante o confinamento, foi passada a informação de que as consultas psicológicas e médicas estavam restritas a teleconsultas; porém, no caso de julgar necessária a consulta presencial, era possível se deslocar com esta justificativa. Inclusive este era um dos itens da Attestation de Déplacement Dérogatoire (MINISTÈRE DE L'INTERIEUR, 2020a). A situação mencionada suscita a refletir que, talvez, em determinadas situaçóes seja difícil para os familiares discernir, no caso de problemas psíquicos, se os sintomas apresentados pelas crianças ou adolescentes são graves ou não.

Segundo Noal e Damásio (2020), o distanciamento social e a abrupta interrupção da rotina para as crianças e os adolescentes que demandam cuidados especializados, como os autistas, aqueles com síndrome de Down, com limitaçóes físicas e que manifestam sofrimento psíquico, podem intensificar os impactos em sua saúde, desde a desorganização sensorial e psicológica até perdas motoras.

A reportagem do Le Parisien (PUEYO, 2020) apresenta a situação de uma família com um adolescente autista, Julien (14 anos), que não fala. Durante o confinamento, o Centro especializado onde ele era atendido foi fechado. $\mathrm{O}$ adolescente, com essa mudança na rotina, se sentiu trancado no apartamento. Sua mãe relata que: "Quando ele viu sua vida de cabeça para baixo, Julien teve uma forte crise. Ele começou a quebrar tudo em nossa casa" (PUEYO, 2020) ${ }^{12}$. A mãe, com o intuito de que ele se acalmasse, levou Julien para dar uma volta no bairro. Ele, então, começou a correr. Foi uma descoberta, pois não sabia correr antes. Desde então, ele passou a querer correr duas a três vezes por dia. A mãe diz que o efeito é benéfico; após correr, fica calmo e relaxado. Lajonquière (2019, p. 50) afirma que "estes tempos de autismos ${ }^{13}$ atuais não propiciam que o adulto venha a interrogar o impossível em torno do qual se articula sua própria relação à criança.” A experiência dessa família mostra como o inusitado da quebra da inércia cotidiana possibilitou a emergência de uma coisa diferente para suportar o confinamento.

I2 En voyant sa vie chamboulée, Julien a fait une grosse crise. Il s'est mis à tout casser chez nous.

I3 Lajonquière se refere a um novo personagem denominado autista que, atualmente, encontramos em todas as partes, ou seja, crianças que recebem o diagnóstico de autismo, mesmo não sendo autistas. 
$\mathrm{Na}$ França, houve a manifestação das famílias e de associações sobre a difícil situação do confinamento para os autistas. Diante deste contexto, no Dia Mundial de Sensibilização para o Autismo (02 de abril), Emmanuel Macron fez um pronunciamento, demonstrando sensibilidade em relação à dificuldade do confinamento para estas pessoas e anunciou que seria feito um formulário adaptado, em que eles poderiam sair com mais frequência que o permitido à população de modo geral (EMMANUEL, 2020).

Além da flexibilidade para sair de casa, foram estruturados lugares específicos para as pessoas com autismo que foram afetadas pela Covid-19. Conforme descreve Cohen (2020) sobre os desafios para a preparação dos profissionais e da unidade de psiquiatria da infância e adolescência da Assistence Publique - Hôpitaux de Paris (AP-HP) para receber os autistas com COVID-19, pois se tratava de uma experiência nova para todos. Apesar das dificuldades encontradas, principalmente a infecção dos profissionais já na primeira semana ( $9 \%$ da equipe), esta unidade recebeu, durante o confinamento, 16 pessoas (entre crianças, adolescentes e adultos): a mais jovem tinha 12 anos e a mais velha 43 anos. Todos os pacientes se recuperaram e receberam alta até o fim do pico da epidemia, apenas um paciente ficou uma semana a mais do que os demais (COHEN, 2020).

É interessante ressaltar que todos os dias do confinamento, às 20 horas os franceses se dirigiam às janelas ou varandas de suas casas para homenagear, com aplausos, os profissionais da saúde que estavam na linha de frente, no combate à Covid-19. Na França, todo o sistema de atendimento emergencial é público, e os aplausos tinham também a intenção de manifestar o desejo em prol do fortalecimento desta rede.

As pessoas com deficiência também foram significativamente afetadas pelo confinamento. Cerca de 100.000 crianças e adolescentes que são acolhidos em institutos médico-educacionais (IME), aproximadamente 60.000 ficaram em suas casas durante o confinamento - Le Parisien (PAYET, 2020). É o caso de Íris (18 anos), com múltiplas deficiências. Essa jovem tem sua mobilidade reduzida, depende de cadeira de rodas para se deslocar, apresenta um retardo cognitivo significativo e sofre de epilepsia. A mãe demonstra muita preocupação, pois, diante da fragilidade da saúde da filha, ela estaria em grande risco com a Covid-19: "A grande 
preocupação é que os prestadores de cuidados que, às vezes, vêm nos ajudar em tempos normais não têm acesso às máscaras. É um verdadeiro escândalo! E eu não quero que eles venham nessas condiçóes, porque acredito que isso pode pôr em risco a Íris" - Le Parisien (PAYET, 2020) ${ }^{14}$.

O confinamento gerou uma grande preocupação para os pais de crianças e adolescentes que necessitam de reabilitação motora e cerebral, pois estes correm o risco de acumular deformidades e regredir. A vida dessas famílias foi gravemente afetada pelo fechamento de escolas, centros de saúde, a impossibilidade de os profissionais de saúde que gravitam em torno dessas crianças continuarem seu trabalho. Isso significa uma ruptura na continuidade do cuidado e dois meses sem reabilitação podem ser catastróficos, conforme explica a mãe de Philippine (5 anos), que teve paralisia cerebral "Eu estava com muito medo de que minha filha perdesse força muscular e habilidades motoras" - 20 Minutes (GABRIEL, 2020) ${ }^{15}$.

O confinamento para as famílias com crianças ou adolescentes com deficiências, autistas, ou que sofrem com outros problemas psíquicos, foi extremamente difícil e preocupante pela falta da estrutura de cuidados específicos. Cada medida de restrição gerou consequências importantes: o fechamento dos centros de atendimento causou retrocesso no processo de tratamento, tanto no que diz respeito à deficiência quando aos problemas psíquicos; e as dificuldades dos profissionais auxiliarem as famílias de modo domiciliar pela falta de equipamentos básicos de proteção, como a máscara, o que impediu o deslocamento e o acesso dos profissionais para atenderem em domicilio e gerou uma preocupaçáo a mais para os pais, os quais se tornaram responsáveis por cuidados específicos de saúde para que seus filhos não sofressem ainda mais danos. Estes são apenas alguns dos itens que devem fazer parte da pauta das autoridades sanitárias, de modo que possam estabelecer formas menos danosas de confinamento a essas pessoas que, em cada caso, necessitam de uma especificidade de cuidado.

14 Le gros souci, c'est que les auxiliaires de vie qui viennent parfois nous aider en temps normal, n'ont pas accès aux masques. 'est un vrai scandale! Et moi je ne souhaite pas q'elles viennent dans ces conditions, car j'estime que cela peut mettre en danger Iris.

15 J'avais très peur que ma fille perde en force musculaire et en motricité, explique Christèle, mère de Philippine. 


\section{A violência velada}

A violência doméstica não aparece nas narrativas das crianças e dos adolescentes destas publicaçóes, provavelmente, por se tratar de um tema complexo em que expor a situação publicamente se caracteriza como uma denúncia, e a vítima pode sofrer represália do agressor. Entretanto, o número de casos de violência doméstica aparece crescentemente nas chamadas para o 119, Service National d'Accueil Téléphonique pour l'Enfance en Danger (SNATED). Conforme o Communique de Presse - Enfance en danger: le gouvernement mobilisé, publicado em 22 de abril de 2020 (MINISTÈRE DE L'INTERIEUR, 2020b), durante a semana de 13 a 19 de abril de 2020, o número de chamadas atingiu 14.531, em comparação com 7.674 do mesmo período de abril de 2019 , um aumento de $89,35 \%$. O crescimento dos números foi relacionado à eficácia de uma campanha de sensibilização do governo destinada ao público em geral, que começou em 30 de março 2020, divulgada nas mídias (televisão, rádio, sites). Nesse documento, consta que 92 crianças foram beneficiadas com o acolhimento temporário de emergência, para garantir sua proteção desde o início do confinamento.

A pesquisa de Campbell (2020) retrata a situação de violência doméstica durante o confinamento em diversos países. Ele chama atenção em relação a supostas violências sofridas pelas crianças e pelos adolescentes que, provavelmente, foram veladas pela situaçáo de confinamento. Esta situação pode possibilitar o aumento da violência doméstica, pois as vítimas passam o tempo todo ao lado do agressor, com possibilidades reduzidas de fazer denúncias. Além de as vítimas não poderem sair de casa para procurar ajuda, os agressores podem vigiá-las permanentemente para que elas não recorram à internet, a mídias sociais ou a celulares para denunciá-los. A pandemia do Covid-19 favorece situaçóes de estresse e fatores de risco, como: desemprego, renda reduzida, recursos limitados, pouco ou nenhum apoio social, aumento do alcoolismo. $\mathrm{O}$ abuso do consumo de bebidas alcoólicas, que é um dos fatores de risco frequentemente relatado pelas vítimas de violência familiar. Devido ao fechamento dos bares e restaurantes, provavelmente haja um maior consumo em casa, o que faz aumentar o risco de violência. Com o confinamento, estáo começando a aparecer em todo o mundo relatos de taxas crescentes de violência doméstica. 
A França indicou um aumento de 30\% nos registros de violência doméstica; já o Brasil estima que os registros de violência doméstica aumentaram de $40 \%$ a $50 \%$. Entretanto, o autor aponta que as organizaçóes que prestam assistência à criança notam uma queda significativa nos relatos de abuso ou negligência infantil. $O$ fato é que esta diminuição pode estar relacionada com a falta de oportunidade de detecção da violência, oposta a uma redução real na incidência. A detecção e as denúncias, muitas vezes, são realizadas pelas escolas ou instituiçóes da comunidade que, na pandemia, se encontram fechadas. No retorno às aulas, os profissionais podem se deparar com um enorme número de crianças que sofreram violência durante o confinamento, e quanto mais o retorno escolar for adiado, este problema pode se agravar significativamente. Esta é uma preocupação que os profissionais de atendimento a vítimas de abuso infantil devem considerar para criar estratégias para atender às necessidades de um grande número de vítimas, alerta Campbell (2020).

A escola é o lugar em que muitas crianças e muitos adolescentes que vivem com recursos precários têm acesso à instrução, à alimentação e a uma série de atividades escolares do mesmo modo que seus colegas de classes sociais mais privilegiadas. As crianças e os adolescentes possuem o direto à educação presencial, bem como a obrigação de ir para escola; assim, restringi-los apenas ao ambiente familiar, mesmo que temporariamente, pode causar prejuízos imensuráveis, como a evasão escolar. Além disso, para alguns estudantes a violência doméstica já faz parte do contexto familiar; com o confinamento, esta situação tende a se agravar. A escola é o lugar onde é possível expressar e obter auxílio para tal situação; portanto, escola fechada pode significar violência velada.

\section{Reflexões finais}

O confinamento significou uma ruptura repentina do cotidiano. No universo da infância e da adolescência, a experiência não foi diferente. As publicaçóes nos jornais franceses e na Radio France Culture forneceram subsídios para se compreender que, com o confinamento, não houve apenas a interdição dos espaços públicos mas do lugar não familiar; obviamente, isso traz implicaçóes ao estado psíquico. Retomando o que explica 
Leandro de Lajonquière, para que uma criança possa crescer e conquistar o lugar de palavra, é interessante que ocorra a circulação entre o familiar e o não familiar, como: frequentar a escola, os parques, andar nas ruas. Este lugar é onde a criança aprende algo diferente daquilo que aprende em sua casa, ela está em contato com outras crianças (colegas, amigos) e outros adultos (professores, pais de amigos, comerciantes) que náo pertencem ao espaço familiar. Esta alternância entre o familiar e o não familiar, e vice-versa é uma circulação indispensável para a questão da estruturação psíquica, segundo a perspectiva psicanalítica. A escola, o parque, as ruas possibilitam que as crianças e os adolescentes transitem entre estes dois lugares. É importante demarcar que o fato de não encontrar mais seus colegas, amigos e professores fez muita falta para eles. Portanto, manter as crianças e os adolescentes confinados apenas no espaço familiar, ou seja, privados deste "outro lugar", intervém no desenvolvimento, na aprendizagem, na saúde psíquica; enfim, implica o processo subjetivo enquanto constituição de sujeito cujo progresso torna-se inviável de ocorrer sem transitar entre esses dois lugares.

Apesar de apresentar esta preocupação com o público infanto-juvenil e apontar inúmeros problemas que sugiram com o confinamento, com o intuito de promover reflexôes sobre esta temática, considero que a minha experiência de viver essa situação do outro lado do oceano me faz afirmar que a França obteve êxito no que diz respeito ao controle da Covid-19. Após 55 dias de confinamento - 17 de março a 11 de maio de 2020 -, foi possível disponibilizar para a população mais leitos. Com a diminuição do contágio, houve menos pressão nos hospitais, distribuição de máscaras à população, acesso ao álcool gel nas ruas e a possibilidade de realizar exames gratuitos para a Covid-19. Hoje em dia, os franceses se preparam para sair de férias - uma espécie de esporte nacional.

No início das etapas do desconfinamento, dia 11 de maio de 2020, a França contava 139.519 casos de pessoas com a Covid-19 e 26.643 fatais (RASTREADOR DA COVID-19, 2020). É indescritível o sofrimento de cada família que perdeu um ente querido por causa da doença. Fatos que demonstram o quanto ainda é um grande desafio para as autoridades públicas, os profissionais e os pesquisadores pensarem melhores estratégias 
em situação de pandemia. A preservação da vida deve ser prioridade em relação a qualquer outra situação; portanto, por mais difícil que tenha sido o confinamento e todos os problemas que dele emergiram, foi a medida que preservou a vida de milhares de pessoas, não apenas na França mas também em diversos outros países.

\section{Agradecimentos}

O presente trabalho foi realizado durante uma bolsa de pós-doutorado apoiada pelo Programa de Cooperação Internacional CAPES-COFECUB (Brasil-França), processo no 88887.333657/2019-00.

\section{Referências}

ANGROSINO, M. Etnografia e observaçáo participante. Porto Alegre: Artmed, 2009.

BADIOU, A. Sobre a situação epidêmica. In: DAVIS, M. et al. (org.). Coronavírus e a luta de classes. Terra sem Amos: Brasil, 2020. p. 35-42.

BERNARD, S. S. et al. First cases of coronavirus disease 2019 (COVID-19) in France: surveillance, investigations and control measures, january 2020. Euro Surveill, v. 25, n. 6, 2020.

CAMPBELL, A. M. An increasing risk of family violence during the Covid-19 pandemic: Strengthening community collaborations to save lives. Forensic Science International: Reports, v. 2, [s. p.], dec. 2020 .

COHEN, D. Apprehender le COVID-19 au fil de l'eau en tant que psychiatre d'enfant et d'adolescent. L'Encephale, v. 46, Issue 3, Supplement, p. S99-S106, june 2020.

CONFINEMENT. Les enfants ressentent intuitivement les angoisses des adultes, ils sont de vraies éponges émotionnelles. Le Monde, 24 abr. 2020. Disponível em:

https://www.lemonde.fr/m-perso/live/2020/04/28/confinement-quel-impact-sur-votre-portemonnaie-racontez-nous-en-direct_6037979_4497916.html. Acesso em: 24 abr. 2020.

EMMANUEL Macron annonce un aménagement du confínement pour les autistes. Le Monde, Paris, 02 abr. 2020. Disponível em: https://www.lemonde.fr/societe/article/2020/04/02/emmanuelmacron-annonce-un-amenagement-du-confinement-pour-les-autistes_6035293_3224.html. Acesso em: 2 abr. 2020.

GABRIEL, O. Coronavirus: Les parents d'enfants handicapés inquiets et épuisés. 20 Minutes, 23 abr. 2020. Disponível em: https://www.20minutes.fr/sante/2764087-20200423-coronavirusparents-enfants-handicapes-inquiets-epuises?fbclid=IwAR17CQSBJmbzZHAfaSM7SOW3EjjS1 m8LkoV0pOWs30zn2ocmJaNKS96H18E._Acesso em: 23 abr. 2020. 
HINE C. Etnografía virtual. Barcelona: Editorial UOC, 2004.

LAJONQUIÈRE, L. (ed.). Figures de l'infantile: la psychanalyse dans la vie quotidienne auprès des enfants. Paris: L'Harmattan, 2013.

LAJONQUIÈRE, L. (ed.). As crianças, a educação e os sonhos adultos em tempos de autismo. Estilos da Clínica, v. 24, n. 1, p. 41-52, 2019.

MANN, C.; STEWARD, F. Internet Communication and Qualitative Research: A Handbook for Researching Online. London: Sage Publications, 2000.

MARTINHAGO, F.; ROMANÍ, O. Risco, biopolítica e governamentalidade: tecnologias de controle social. Gavagai, Erechim, v. 6, n. 2, p. 56-71, 2019.

MINISTÈRE DE L'INTERIEUR. Attestation de Déplacement Dérogatoire. Paris, 2020a. Disponível em: https://mobile.interieur.gouv.fr/Actualites/L-actu-du-Ministere/Attestation-dedeplacement-et-de-voyage. Acesso em: 28 maio 2020.

MINISTÈRE DE L'INTERIEUR. Communique de Presse - Enfance en danger: le gouvernement mobilisé. Paris, 22 abr. 2020b. Disponível em: https://www.interieur.gouv.fr/Actualites/ Communiques/Enfance-en-danger-le-Gouvernement-mobilise. Acesso em: 22 maio 2020.

MOGHADDAM F. Confinement chez les enfants : Transposer autant qu'on le peut la vie d'avant à l'intérieur. Radio France Culture, Paris, 06 abr. 2020. Disponível em: https://www.franceculture. $\mathrm{fr} /$ societe/confinement-chez-les-enfants-transposer-autant-quon-le-peut-la-vie-davant-a-linterieur Acesso em: 6 abr. 2020.

MORAND, A. et al. COVID-19 virus and children: What do we know? Archives de Pédiatrie, n. 27, p. $117-118,2020$.

NOAL, D.; DAMÁSIO, F. (coord.). Crianças na Pandemia Covid-19. Brasília: Ministério da Saúde, 2020.

PAYET, M. Coronavirus: l'inquiétude des parents d'enfants handicapés. Le Parisien. Paris, 28 mar. 2020. Disponível em: https://www.leparisien.fr/societe/coronavirus-l-inquietude-des-parentsd-enfants-handicapes-28-03-2020-8289675.php._Acesso em: 28 mar. 2020.

PUEYO, S. Confinement: un jeune autiste de l'Isère découvre le plaisir de la course à pied. Le Parisien, Paris, 24 abr. 2020. Disponível em: https://www.leparisien.fr/societe/sante/confinementun-jeune-autiste-de-l-isere-decouvre-le-plaisir-de-la-course-a-pied-24-04-2020-8305113. php?fbclid=IwAR13_Mhp086AjC62AdWOx03tEh7qhnxvK7Si6MkaeoDCuHX0ui15pJP2v-U. Acesso em: 24 abr. 2020.

RASTREADOR DA COVID-19. 2020. Disponível em: <https://www.bing.com/covid/local/ france? timeline=1. Acesso em: 6 jun. 2020.

REALE, C. L. Enfants confinés: On n'a plus trop de moments de liberté. Radio France Culture, Paris, 10 abr. 2020. Disponível em: https://www.franceculture.fr/societe/enfants-confines-na-plustrop-de-moments-de-liberte. Acesso em: 10 abr. 2020. 
RODRIGUES, R.; REIS, M. A ilusão (psico)pedagógica e o empobrecimento das experiências educativas (entrevista a Leandro de Lajonquière). Estilos da Clínica, v. 23, n. 2, p. 430-450, 2018.

TAVEIRA, C. Hélène Romano, psychologue le confinement va entraîner une hausse des comportements agressifs et des suicides. CNews, 18 mar. 2020. Disponível em: https://www.cnews. fr/france/2020-03-18/helene-romano-psychologue-le-confinement-va-entrainer-une-hausse-descomportements. Acesso em: 18 mar. 2020.

TOURRET, L. Faire face aux tensions du confinement avec les adolescents. Radio France Culture, Paris, 09 mar. 2020. Disponível em: https://www.franceculture.fr/emissions/radiographies-ducoronavirus/comment-faire-face-aux-tensions-avec-son-adolescent-confine. Acesso em: 9 mar. 2020 .

VECRIN, A. Le risque psychique du confinement risque de dépasser le risque sanitaire. Libération, 15 abr. 2020. Disponível em: https:/www.liberation.fr/debats/2020/04/15/le-risque-humain-etpsychique-du-confinement-risque-de-depasser-le-risque-sanitaire_1785280. Acesso em: 15 abr. 2020 .

VINER, R. M. et al. School closure and management practices during coronavirus outbreaks including COVID-19: a rapid systematic review. Lancet Child Adolesc Health, v. 4, n. 5, p. 39404, 2020.

WORLD HEALTH ORGANIZATION (WHO). Novel coronavirus China. Disease outbreak news. Geneva: WHO; 12 jan. 2020. 2020a. Disponível: https://www.who.int/csr/don/12-january2020-novel-coronavirus-china/en/. Acesso em: 22 maio 2020.

WORLD HEALTH ORGANIZATION (WHO). Director-General's opening remarks at the media briefing on COVID-19 - 11 march 2020. Geneva: WHO; 11 march 2020b. Disponível em: https://www.who.int/dg/speeches/detail/who-director-general-s-opening-remarks-at-the-mediabriefing-on-covid-19---11-march-2020. Acesso em: 22 maio 2020.

Recebido: 30/06/2020

Aceito: $03 / 08 / 2020$ 


\section{Confinement across the ocean: the experience of children and adolescents during the Covid-19 epidemic in France}

\section{Abstract}

The present article presents data that portray the confinement in France during the Covid-19 epidemic, precisely, for the children and youth public. The aim of this study was to provide some elements that make it possible to advance in the understanding of how children and adolescents experienced the experience of confinement in France. The methodology chosen for the development of the research was virtual ethnography. Through the materials published in the French newspapers and on the website of radio France Culture it was possible to have contact with the experiences lived by the families in the confinement. These publications provided subsidies to understand that keeping children and adolescents confined only in the family space, that is, deprived of the unfamiliar place (schools, parks, streets), implies the subjective process as the constitution of a subject, whose progress becomes impossible to happen without moving between these two places.

keywords: Children. Adolescents. Covid-19. Confinement. Epidemic. 